REFLECTION

\title{
Health Care Reform and Equity: Promise, Pitfalls, and Prescriptions
}

\author{
Kevin Fiscella, MD, MPH
}

Departments of Family Medicine and Community \& Preventive Medicine, University of Rochester, Rochester, NY
Conflict of interest: Dr Fiscella served on the Institute of Medicine Committee on Future Directions for the National Health Care Quality and Disparities Report and bas consulted for the Health Resources Services Administration

\section{CORRESPONDING AUTHOR}

Kevin Fiscella, MD, MPH

1381 South Ave

Rochester, NY 14620

Kevin_Fiscella@URMC.rochester.edu

\begin{abstract}
The United States has made little progress during the past decade in addressing health care disparities. Recent health care reforms offer an historic opportunity to create a more equitable health care system. Key elements of health care reform relevant to promoting equity include access, support for primary care, enhanced health information technology, new payment models, a national quality strategy informed by research, and federal requirements for health care disparity monitoring. With effective implementation, improved alignment of resources with patient needs, and most importantly, revitalization of primary care, these reforms could measurably improve equity.
\end{abstract}

Ann Fam Med 2011;9:78-84. doi:10.1370/afm.1213.

\section{INTRODUCTION}

7 he United States has made little progress toward greater equity in health care quality according to the annual National Health Care Disparities Reports. ${ }^{1}$ Recent health care reforms offer an historic opportunity to make inroads. In this commentary, I review key provisions of these reforms, particularly those in the Patient Protection and Affordable Care Act, often shortened to Affordable Care Act (ACA) of 2010, ${ }^{2}$ and discuss their potential promise, pitfalls, and steps (prescriptions) needed to jumpstart progress toward more equitable health care (Table 1). I begin by briefly reviewing causes of health care disparities and then discuss selected, key health care reform provisions within 6 interlocking domains: access related to insurance coverage and costs, strengthening primary care, improvements in health information technology, changes in physician payment, adoption of a national quality, and improved disparity monitoring and accountability.

\section{CAUSES OF HEALTH CARE DISPARITIES}

Health care disparities related to race, ethnicity, socioeconomic status (SES), and markers of social disadvantage result from a complex confluence of patient, clinician, and system levels factors. ${ }^{3}$ These disparities often reflect reciprocal influences between social stratification and ensuing social disadvantage and worse health ${ }^{4}$; unconscious clinician bias toward socially disadvantaged persons ${ }^{5,6} ;$ separate and often unequal care ${ }^{7-10} ;$ and a health care system, including primary care, ${ }^{11}$ that is ill-equipped to address the often complex needs of socially disadvantaged patients, who often become underserved patients. ${ }^{12}$

Equitable health care means more than elimination of bias, it also means creation of patient-centered systems of care that support healing and caring relationships that are responsive to patients' needs, wishes, and context. ${ }^{13}$ Improving equity requires aligning health care resources and capability with patient needs, particularly patients who have been historically underserved. ${ }^{12}$ 
Table 1. Promise, Pitfalls, and Prescriptions for Improved Equity Under Health Reform

\begin{tabular}{llll}
\hline $\begin{array}{l}\text { Health Reform } \\
\text { Provision }\end{array} \quad$ Promise & Pitfall & Prescription
\end{tabular}

Access (insurance and costs)

Expanded coverage Coverage for up to 32 million uninsured

Behavioral health parity

Reduced cost barriers

Elimination of co-payments for evidence-

based preventive care

Reduce cost barriers

Revitalization of primary care including the safety net Improved physician

payments

Elimination in Medicare-

Medicaid payment

differences

Bonus for work in short-

age areas

National Health

Care Work Force

Commission

Improvement in federal

load repayment

Collaborative Care

Network

Piloting of new care models

Modest improvement in resources

Potential to minimize separate and unequal systems

Modest impact on physician maldistribution

Potential to influence work force maldistribution

Improved recruitment to shortage areas

Improvement in care coordination for underserved

Spark innovation

State-operated health

insurance exchanges

Health information technolog

Incentives for physicians Acceleration of diffusion

and hospitals nearing tipping point

Payment model reform

Payment Advisory Board

National Pilot Medicare

Payment Program

Potential move from volume to value payment

Potential for changes in primary care payment

Piloting of bundled payments

National quality strategy

Formal national quality improvement strategy

Reporting of perfor-

mance by federal

programs

Monitoring disparities

Enhance collection of disparity data within health care

Analyze disparities trends

Potential to integrate multiple elements of health reform

Improved accountability for programs for underserved

Improved detection of disparities

Identification of key disparities for targeted action
Need for robust primary care system Remaining 23 million uninsured

Absence of "public option" undermines cost control for care for previously uninsured

Does not address barriers related to stigma related to mental health care

May accelerate trends toward cost shifting to patients for medical and behavioral care, worsening disparities

Not sufficient to generate practice adaptive reserve for transformation

Does not address gap between Medicare and private insurance payments.

Too small to have significant effect

Depends on authority of commission to affect key issues

Does not address retention following fulfillment of commitment

Need for vibrant primary care safety

net to coordinate care

Modest investments may not be sufficient

Practice change is a continuous process

Not all states will opt for innovation

Does not ensure improvement in quality

Digital divide by practice and patient

Success dependent on members of board

Relatively small change

Unknown impact of bundled payments on primary care

Potential adverse impact on underserved

Potential for neglect of the physicianpatient relationship

Inadequate funding for implementation and PBRN research, particularly in safety-net practices

Assessing disparities does not assure they are addressed

Monitoring alone is not sufficient
Revitalize primary care

Universal coverage

Expansion of Medicare eligibility and other public options

Integrate behavioral health services into primary care

Restrict cost sharing based on percent family income

Major payment reform

Eliminate differences in payment by insurance type.

Prohibit segregation of care based on payment type within health care systems that receive federal funds.

Comprehensive strategy to primary care and workforce issues

Address student selection, training, payments, and quality of practice in shortage areas

Enhance quality of practice and payment

Strengthen adaptive reserve of safety net

Support innovation in all practices

Greater funding for practice-based research for underserved

Funding for primary care extension programs

Support for quality improvement collaboratives that leverage health information technology

Subsidies for safety-net practices and training and support for patients in use of health information technology

Major changes in needed in quantity and type of financing for primary care

Build in monitoring of effects on care for underserved patients
Need to keep patient and relationships at fore

Improved funding for practice-based research, particularly safety-net practices

Build in continuous loops between reporting, policy/intervention and follow-up

DHHS should hold federally sponsored programs accountable for progress in addressing disparities 


\section{ACCESS}

Improving equity begins with improving health care system access. System access is strongly affected by insurance coverage and cost. Minority and low-SES patients are more often uninsured than their counterparts. ${ }^{1}$ Lack of health insurance is a major contributor to health care disparities ${ }^{14}$; health care disparities are smaller in such health systems as the Veterans Affairs, where access is more uniform. ${ }^{15}$ ACA provisions will eventually expand insurance coverage to an estimated 32 million uninsured persons, but the Congressional Budget Office estimates that health care reform may still leave 23 million persons, including undocumented immigrants, without any coverage. ${ }^{16}$

Recent reforms also offer potential for improving access to behavioral care for poor and minority patients and for addressing disparities in behavioral health utilization. ${ }^{1}$ Cost represents a key barrier. Parity provisions in the Mental Health Parity and Addiction Equity (MHPAE) Act of 2008 (https://www.cms.gov/ healthinsreformforconsume/04_thementalhealthparityact.asp) and ACA minimize cost differences between behavioral and medical care. Specifically, MHPAE prohibits health plans from imposing deductibles, co-payments, and out-of-pocket limits on mental health and substance abuse coverage that are higher than those imposed for medical-surgical coverage. It also prohibits restrictions on days of hospital coverage and duration and scope of behavioral treatment beyond limits that health plans impose for medical-surgical coverage. Access to behavioral health care for underserved groups could be further enhanced through creation of integrated primary and behavioral health care similar to the Veterans Affairs health system. ${ }^{17}$

Health care costs contribute to disparities, even among the insured..$^{18}$ Insurance deductibles and co-payments discourage appropriate health care use, ${ }^{19}$ affecting those with the least income. ACA will eliminate patient cost sharing for evidence-based preventive services covered by Medicare and Medicaid. It also authorizes Medicare coverage for annual health assessments and eventually eliminates the so-called donut hole in Medicare part D prescription coverage. Prohibitions against exclusions for preexisting conditions and lifetime limits on spending by health plans may provide greater benefit to low-SES patients who are more often affected by chronic conditions. ${ }^{20}$ These changes may also reduce physician decision-making time devoted to patients' ability to pay ${ }^{21}$ and may incrementally move the country toward improved health care equity. Potential benefits of these changes, however, may be undermined by trends toward increased patient cost sharing. ${ }^{22}$ Cost sharing disproportionately affects low-income patients. ${ }^{23}$ Premiums for obtaining insurance though health insurance exchanges for the uninsured will be based on household income, but many low-income workers may continue to pay high premiums for employer-based coverage.

\section{PRIMARY CARE}

Access to primary care is associated with fewer disparities in outcomes. ${ }^{24} \mathrm{~A}$ robust primary care system is the cornerstone for a more equitable health care system. Longitudinal, caring relationships with patients provide the opportunity to minimize stereotypes and foster patient enablement and capability, potentially yielding more equitable care. ${ }^{25,26}$

Revitalization of primary care is critical to health reform success. ${ }^{27}$ ACA takes important, although modest steps, in addressing critical primary care needs: payment reform, enhancing the training pipeline, transforming practice, and buttressing the primary care safety net. ACA provisions include establishment of a National Health Care Workforce Commission, increased support for workforce training (Title VII and the Prevention and Public Health Fund), cultural competency training, enhanced payments, expansion of health centers, and piloting of new care models. ACA also provides bonus payments to primary care physicians under Medicare and eliminates differences in payments between Medicaid and Medicare for primary care. It further provides Medicare bonuses to primary care physicians who work in shortage areas, helping to minimize geographically related disparities. These reforms may begin to minimize disparities in resources between primary care practices whose patient populations differ by social disadvantage. These reforms could also conceivably reduce de facto segregation in health care by insurance type (eg, faculty practices vs clinics), although federal regulations prohibiting intra-institutional segregation of care by insurance type within systems receiving federal funding may be needed. To be sure, modest increases in payments alone will not be sufficient to address the maldistribution of primary care physicians, much less avert a primary care shortage. ${ }^{28}$

Poor and minority patients are at greater risk for lacking primary care; those with access are more often seen within resource-strapped safety-net practices, such as federally qualified community health centers (FQHCs), hospital clinics, and a small portion of community physicians. ${ }^{7,29}$ Strengthening the primary care safety net is critical to ensuring access after expansion of insurance coverage.

FQHCs are the most important source of primary care for underserved patients, currently serving 20 million patients who are largely minority and of low income. ${ }^{30}$ FQHCs will likely remain the key source for primary care to underserved groups under health care 
reform. ${ }^{30} \mathrm{ACA}$ invests heavily ( $\$ 11$ billion) in FQHC expansion, potentially doubling the number of patients served. Annual federal loan repayment for physicians working in underserved areas increases to $\$ 50,000$ (from $\$ 35,000$ ), part-time practice is now permitted, and teaching time within $\mathrm{FQHC}$ is now counted for repayment. Furthermore, ACA supports establishing new teaching health centers and provides new systems of payment for this teaching.

These investments alone are not sufficient to ensure transformation of care within FQHCs. Enhancement in health center financing will be needed to generate an adaptive reserve (ie, capability of practices to implement and sustain change) ${ }^{31}$ to facilitate FQHC practice redesign. ${ }^{32}$ Federal support is needed to sustain and advance quality improvements previously initiated through the Health Disparities Collaboratives. ${ }^{33}$ Innovative training programs are also needed to develop future medical home leaders for the underserved. ${ }^{34}$

ACA also supports establishment of the community-based Collaborative Care Network Program to support local consortia of health care providers (including health centers) to coordinate and integrate health care services for low-income uninsured and underinsured patients. Potentially, this provision could foster innovative, community-wide solutions for care for underserved patients, including promotion of patient capability. ${ }^{35}$ Success will depend on the strength of local partnerships and creation of sustainable models of primary care delivery that effectively coordinate use of community resources.

ACA aims to transform health care quality (including primary care) through a series of small but potentially synergistic steps. ${ }^{27}$ It promotes piloting of new care models, including medical homes, chronic disease management teams, and integration of medical and behavioral health care. State-run health insurance exchanges provide states with the opportunity to establish new primary care models. If successful, these models could reinvigorate primary care while creating systems of care that provide the time, resources, and capability needed to respond to the needs of underserved patients. ${ }^{11,36}$

The path to transformation will not be easy. As the Patient-Centered Medical Home National Demonstration Project has shown, transformation is a slow, challenging process, requiring high motivation and often external support. ${ }^{31}$ Toward this end, ACA authorizes the creation, but no corresponding funding, for primary care extension programs designed to assist primary care practices in quality improvement. ${ }^{37}$ Funding for this program is critical if primary care is take full advantage of reforms. Without buttressing key resources in primary care and addressing adaptive reserve within practices, ${ }^{38}$ the combined stress of care for more (newly insured) patients coupled with pressure to transform practice, could undermine patients' care, demoralize primary care clinicians, and hinder progress toward a more equitable system.

\section{HEALTH INFORMATION TECHNOLOGY}

Adequate health information technology, including availability of electronic health records (EHRs), is one of the pillars for transforming primary care and improving health care quality and equality. ${ }^{39}$ Adoption has been relatively slow, but a tipping point may be near. By 2009, $44 \%$ of office physicians in the United States reported use of some type of EHRs. ${ }^{40} \mathrm{With}$ funding through the American Recovery Reinvestment Act (ARRA) of 2009 (http://www.recovery.gov/About/Pages/The_Act.aspx), physicians and hospitals will receive financial incentives through Medicaid or Medicare for acquiring and engaging in federally defined meaningful use of EHRs. Federal certification of EHR vendors for meaningful use should spur improvements in EHRs. ${ }^{41}$ Features, if sufficiently user-friendly, such as patient registries, reminders, decision support, computerized order entry, and electronic prescribing, offer the potential for improving equity through improved tracking, population management, standardization of care, and possibly reduced decisionmaking bias. ${ }^{42}$ Establishment of regional Health Information Technology Extension programs and Beacon Community Cooperative Agreement programs may further facilitate technology diffusion, infrastructure, and exchange capabilities within regions across the country.

Slower diffusion of this technology to practices serving minority patients, however, could have the unintended consequence of worsening health care disparities by further widening inequalities in resources between providers. ${ }^{43}$ In addition, powerful incentives may be needed to promote effective information exchange between systems and between patients and providers. Last, in the absence of targeted initiatives, the digital divide in knowledge and access to technology could worsen disparities when practices begin to implement online scheduling, patient portals, and patient health records. ${ }^{44}$

\section{PAYMENT MODELS}

New payment models may potentially promote equity by fostering quality improvement, including the development of new care models, such as the patient home, potentially better suited to meet the needs of poor and minority patients. ${ }^{11}$ Payment systems that reward payment for health care value (ie, better quality relative to cost) rather than volume might produce better alignment between patient needs and resources. 
ACA innovations designed to enhance value include allowing providers who are organized as accountable care organizations to share in cost savings, creation of an innovation center within Centers for Medicare and Medicaid Services (CMS), establishment of an independent payment advisory board, reduction in hospital payments for hospital-acquired conditions, and establishment of a national Medicare pilot program to develop and evaluate bundled payments (a type of limited capitation). Provided that bundled payments take into account the greater health care needs of underserved patients and do not penalize safety-net providers, ${ }^{45}$ they offer the potential for promoting equity by redirecting resources to health care value and population health. As with any major reform, however, unintended consequences are possible. Implementation of bundled payments could discourage accountable care organizations from enrolling underserved patients because these organizations may fear potentially higher costs, unless payments take into account patients' social disadvantage in addition to case-mix. ${ }^{46}$ Bundled payments could also undermine the sustainability of small private practices that often provide care to underserved patients in many rural communities.

\section{A NATIONAL HEALTH CARE QUALITY STRATEGY}

Equity represents a core dimension of health care quality. ${ }^{47}$ Efforts to promote health care quality offer potential for promoting equity, particularly if efforts include explicit focus on addressing disparities ${ }^{48}$ or produce "zero defects." 49 ACA directs the Secretary of the Department of Health and Human Services (DHHS) to develop a national quality improvement strategy including selecting and reporting on uniform quality measures by federally sponsored programs. The secretary has charged the Agency for Healthcare Research and Quality (AHRQ) with leading this effort. The appointment of quality improvement maven, Donald Berwick, to lead CMS may further energize health care reforms. ACA calls for equity to be one of the considerations in the development and selection of quality of measures. Improved measurement of quality and equity could focus more attention and resources on addressing health care disparities and aligning resources with needs.

A shift in federal research funding priorities is necessary, however, to fully enable a national strategy to improve health care quality and reduce disparities. ${ }^{50}$ In 2007 , the United States spent $4.5 \%$ of total health care expenditures on biomedical research, but only $0.1 \%$ on health services research. ${ }^{51}$ The National Institute of Health (NIH) director, Francis Collins has made research relevant to health reform an $\mathrm{NIH}$ priority, ${ }^{52}$ but this new NIH priority presumably refers mainly to comparative effectiveness research rather than research designed to optimize health care delivery. The ACA has also upgraded the National Center on Minority Health to an NIH institute. Although this change bodes well for improved community-based health disparities research, it is not clear whether it will shift funding toward health care disparities research. A center of innovation will be established within CMS. Even so, developing and implementing a national quality and disparity strategy will require adequate and stable PBRN funding (eg, to support practice facilitators who can boost practices' adaptive reserve), particularly implementation of new care models within safety-net practices. ${ }^{53}$ Given the growing federal investment in FQHCs and their pivotal role in addressing disparities, research funding is needed to inform optimal care delivery models in these sites.

\section{MONITORING HEALTH CARE DISPARITIES}

ACA directs DHHS to evaluate health and health care systems to enhance collection and reporting of health care data by race, ethnicity, sex, primary language, disability, and rural residence. Similar directives are included in EHR meaningful use requirements. Availability of these data will facilitate better assessment and implementation of interventions to address disparities by health plans and hospitals. ${ }^{54}$ ACA directs DHHS to analyze data to detect and monitor trends in health disparities for each federally conducted or supported health care or public health program or activity. These requirements may facilitate greater accountability for assessing and addressing health care disparities within federally sponsored programs. With sufficient commitment from DHHS leadership, this requirement could potentially result in a systematic effort by federally sponsored programs to publicly report on and address health care disparities within their programs. These efforts could be aided by changes in the National Healthcare Quality Report and National Healthcare Disparity reports recommended by the Institute of Medicine. ${ }^{55}$ Included are national priorities in areas of quality and disparities, improved actionability including accountability, and an expanded quality framework that includes the domains of health care access and health care infrastructure required to improve quality and equity. Closing the feedback loop between quality and equity reporting and corrective federal, state, and local policies will be critical given the enormous complexity of reforms.

\section{CONCLUDING THOUGHTS}

Health care reforms, many not slated for enactment until 2014, offer an unprecedented opportunity to cre- 
ate a more equitable patient-responsive health care system. ACA targets access by expanding insurance coverage and the FQHC safety net. Further legislation will be required to address access for the remaining 23 million uninsured. Other provisions related to costs may improve equity, but trends toward greater patient cost sharing may offset gains unless ways are found to mitigate their impact on low-income persons.

Health reform also offers promise in a number of areas besides system access, including primary care, health information technology, payment reform, a national quality strategy, and disparity monitoring.

Two fundamental challenges lie in the way. The first challenge is aligning health care resources with patients needs. At the level of the patient visit, ${ }_{1}^{11}$ practice, ${ }^{7}$ and hospital, ${ }^{9}$ resources are misaligned. ${ }^{12}$ Health care reform takes small steps toward addressing this problem, but trends toward pay for performance and bundled payment could worsen this mismatch if they fail to account for the needs of underserved patients and practices serving them. ${ }^{56,57}$ Ultimately, systems of payments must account for patient morbidity as well as patient complexity ${ }^{58}$ including contextual capability related to language, culture, health literacy, and disempowerment.

The second challenge relates to revitalization of primary care, particularly for underserved patients. Whether health reform promotes equity may depend partly on how health reforms affect key relationships, not only between clinicians and patients, but also between clinicians and other team members. This means creating systems that provide the time, space, and interpersonal relationships necessary to ensure high quality primary care. It also means creating primary care teams in which all members' experience and training are optimally utilized. ${ }^{59}$ With the diffusion of health information technology and emerging changes in payment, transformation to team-based care may prove to be primary care's greatest challenge. Emerging data suggest that teams improve patients' health status. ${ }^{60}$ Transformation to team care, however, is enormously challenging. Transforming primary care requires not only major changes in medical training ${ }^{61}$ but also supportive infrastructure, such as primary care extension programs and learning collaboratives. Federal agencies charged with implementing health reform should take notice.

Assuming health care reforms survive the looming political and legal land mines during the next four years, primary care will likely confront a period of extraordinary change. Success in creating a more equitable and patient-responsive health care system may depend in part on our ability as primary care clinicians to seize these opportunities and champion systems of care responsive to the needs of all patients.
To read or post commentaries in response to this article, see it online at http://www.annfammed.org/cgi/content/full/9/1/78.

Key words: Healthcare disparities; health care reform; primary care; health policy

Submitted July 20, 2010; submitted, revised, October 18, 2010; accepted November 7, 2010.

Acknowledgement: Adjuah van Keken assisted with the preparation of this manuscript.

\section{References}

1. AHRQ. 2009 National Healthcare Quality \& Disparities Reports. http://www.ahrq.gov/qual/qrdr09.htm. Accessed Oct 5, 2010.

2. Henry J Kaiser Foundation. Summary of New Health Reform Law. http://www.kff.org/healthreform/upload/8061.pdf. http://healthreform.kff.org/document-finder/patient-protection-and-affordable. Accessed Oct 5, 2010.

3. Institute of Medicine. Unequal Treatment: Confronting Racial and Ethnic Disparities in Health Care. Washington, DC: National Academy Press; 2002.

4. Sidanius J, Pratto F. Social Dominance: An Intergroup Theory of Social Hierarchy and Oppression. Cambridge, MA: Cambridge University Press; 1999.

5. Burgess DJ. Are providers more likely to contribute to healthcare disparities under high levels of cognitive load? How features of the healthcare setting may lead to biases in medical decision making. Med Decis Making. 2010;30(2):246-257.

6 . Fiske ST. Intent and ordinary bias: unintended thought and social motivation create casual prejudice. Soc Justice Res. 2004;17(2):117-127.

7. Bach PB, Pham HH, Schrag D, Tate RC, Hargraves JL. Primary care physicians who treat blacks and whites. N Engl J Med. 2004;351(6): 575-584.

8. Mehta RH, Liang L, Karve AM, et al. Association of patient casemix adjustment, hospital process performance rankings, and eligibility for financial incentives. JAMA. 2008;300(16):1897-1903.

9. Hasnain-Wynia R, Baker DW, Nerenz D, et al. Disparities in health care are driven by where minority patients seek care: examination of the hospital quality alliance measures. Arch Intern Med. 2007; 167(12):1233-1239.

10. Varkey AB, Manwell LB, Williams ES, et al; MEMO Investigators. Separate and unequal: clinics where minority and nonminority patients receive primary care. Arch Intern Med. 2009;169(3):243-250.

11. Fiscella K, Epstein RM. So much to do, so little time: care for the socially disadvantaged and the 15-minute visit. Arch Intern Med. 2008;168(17):1843-1852.

12. Fiscella $K$, Shin $P$. The inverse care law: implications for healthcare of vulnerable populations. J Ambul Care Manage. 2005;28(4):304-312.

13. Epstein RM, Fiscella K, Lesser CS, Stange KC. Why the nation needs a policy push on patient-centered health care. Health Aff (Millwood). 2010;29(8):1489-1495.

14. Lillie-Blanton M, Hoffman C. The role of health insurance coverage in reducing racial/ethnic disparities in health care. Health Aff (Millwood). 2005;24(2):398-408.

15. Saha S, Freeman M, Toure J, Tippens KM, Weeks C, Ibrahim SA. Racial and ethnic disparities in the VA health care system: a systematic review. J Gen Intern Med. 2008;23(5):654-671.

16. Congressional Budget Office. Table 2. Preliminary Estimate of the Effects of Insurance Coverage Provisions on the Reconciliation Legislative Combined with H.R. 3590 as Passed by the Senate. http://www. cbo.gov/ftpdocs/113xx/doc11355/hr4872.pdf. Accessed Oct 5, 2010.

17. Zeiss AM, Karlin BE. Integrating mental health and primary care services in the Department of Veterans Affairs health care system. J Clin Psychol Med Settings. 2008;15(1):73-78. 
18. Trivedi AN, Rakowski W, Ayanian JZ. Effect of cost sharing on screening mammography in Medicare health plans. $N$ Engl J Med. 2008;358(4):375-383

19. Solomon MD, Goldman DP, Joyce GF, Escarce JJ. Cost sharing and the initiation of drug therapy for the chronically ill. Arch Intern Med. 2009;169(8):740-748, discussion 748-749.

20. Sebastian C, Baily K, Stoll K. Health Reform: Help for Families with Pre-Existing Conditions. Washington, DC: Families USA; 2010.

21. Bernheim SM, Ross JS, Krumholz HM, Bradley EH. Influence of patients' socioeconomic status on clinical management decisions: a qualitative study. Ann Fam Med. 2008;6(1):53-59.

22. Claxton G, DiJulio B, Whitmore $\mathrm{H}$, et al. Health benefits in 2010: premiums rise modestly, workers pay more toward coverage. Health Aff (Millwood). 2010;29(10):1942-1950.

23. Cunningham PJ. Chronic burdens: the persistently high out-ofpocket health care expenses faced by many Americans with chronic conditions. Issue Brief (Commonw Fund). 2009;63:1-14.

24. Starfield B, Shi L, Macinko J. Contribution of primary care to health systems and health. Milbank Q. 2005;83(3):457-502.

25. Ferrer RL. Pursuing equity: contact with primary care and specialist clinicians by demographics, insurance, and health status. Ann Fam Med. 2007;5(6):492-502.

26. Mercer SW, Neumann M, Wirtz M, Fitzpatrick B, Vojt G. General practitioner empathy, patient enablement, and patient-reported outcomes in primary care in an area of high socio-economic deprivation in Scotland-a pilot prospective study using structural equation modeling. Pat Educ Counsel. 2008;73(2):240-245.

27. Kocher R, Emanuel EJ, DeParle NA. The Affordable Care Act and the future of clinical medicine: the opportunities and challenges. Ann Intern Med. 2010;153(8):536-539.

28. Steinbrook R. Easing the shortage in adult primary care-is it all about money? N Engl J Med. 2009;360(26):2696-2699.

29. Shi L. Experience of primary care by racial and ethnic groups in the United States. Med Care. 1999;37(10):1068-1077.

30. Adashi EY, Geiger HJ, Fine MD. Health care reform and primary care-the growing importance of the community health center. N Engl J Med. 2010;362(22):2047-2050.

31. Crabtree BF, Nutting PA, Miller WL, Stange KC, Stewart EE, Jaén CR. Summary of the National Demonstration Project and recommendations for the patient-centered medical home. Ann Fam Med. 2010;8(Suppl 1):S80-S90, S92.

32. Shin P, Ku L, Jones E, Finnegan B, Rosenbaum S. Financing Community Health Centers as Patient and Community Centered Medical Homes: A Primer. Washington, DC: Commonwealth Fund; 2009. http://www. gwumc.edu/sphhs/departments/healthpolicy/dhp_publications/ pub_uploads/dhpPublication_A186E838-5056-9D20-3D9EA92EB 75DAC24.pdf. Accessed Oct 12, 2010

33. Chin $M H$, Kirchhoff $A C$, Schlotthauer $A E$, et al. Sustaining quality improvement in community health centers: perceptions of leaders and staff. J Ambul Care Manage. 2008;31(4):319-329.

34. Markuns JF, Culpepper L, Halpin WJ Jr. Commentary: A need for leadership in primary health care for the underserved: a call to action. Acad Med. 2009;84(10):1325-1327.

35. Ferrer RL, Carrasco AV. Capability and clinical success. Ann Fam Med. 2010;8(5):454-460.

36. Fiscella K. Eliminating disparities in health care through quality improvement. In: Williams R, ed. Eliminating Healthcare Disparities in America: Beyond the IOM Report. Totowa: Humana Press; 2007.

37. Grumbach K, Mold JW. A health care cooperative extension service: transforming primary care and community health. JAMA 2009;301(24):2589-2591.

38. Nutting PA, Crabtree BF, Stewart EE, et al. Effect of facilitation on practice outcomes in the National Demonstration Project model of the patient-centered medical home. Ann Fam Med. 2010;8(Suppl 1): S33-S44, S92.
39. Bodenheimer T, Grumbach K. Electronic technology: a spark to revitalize primary care? JAMA. 2003;290(2):259-264.

40. Hsiao (-J, Beatty PC, Hing ES, Woodwell DA, Rechtsteiner EA, Sisk JE. Electronic Medical Record/Electronic Health Record Use by Officebased Physicians: United States, 2008 and Preliminary 2009. Hyattsville, MD: National Center for Health Statistics, Centers for Disease Control and Prevention; 2009. http://www.cdc.gov/nchs/data/hestat/ emr_ehr/emr_ehr.htm. Accesssed Oct 5, 2010.

41. Blumenthal D. Stimulating the adoption of health information technology. N Engl J Med. 2009;360(15):1477-1479.

42. Taplin SH, Rollason D, Camp A, diDonato K, Maggenheimer E. Imagining an electronic medical record for turning cancer screening knowledge into practice. Am J Prev Med. 2010;38(1):89-97.

43. Hing $E$, Burt CW. Are there patient disparities when electronic health records are adopted? J Health Care Poor Underserved. 2009. 20(2):473-488.

44. Gibbons MC, Rivera Casale C. Reducing disparities in health care quality: the role of health it in underresourced settings. Med Care Res Review. 2010;67(5 suppl):155S-162S.

45. Wang CJ, Conroy KN, Zuckerman B. Payment reform for safetynet institutions-improving quality and outcomes. N Engl J Med. 2009;361(19):1821-1823.

46. Hamilton BH. HMO selection and Medicare costs: Bayesian MCMC estimation of a robust panel data tobit model with survival. Health Econ. 1999;8(5):403-414.

47. Institute of Medicine. Crossing the Quality Chasm: A New Health System for the 21st Century. Washington, DC: National Academy Press; 2001.

48. Fiscella K, Franks P, Gold MR, Clancy CM. Inequality in quality: addressing socioeconomic, racial, and ethnic disparities in health care. JAMA. 2000;283(19):2579-2584

49. Cohen MG, Fonarow GC, Peterson ED, et al. Racial and ethnic differences in the treatment of acute myocardial infarction: findings from the Get With the Guidelines-Coronary Artery Disease program. Circulation. 2010;121(21):2294-2301.

50. Westfall JM, Mold J, Fagnan L. Practice-based research-"Blue Highways" on the NIH roadmap. JAMA. 2007;297(4):403-406.

51. Dorsey ER, de Roulet J, Thompson JP, et al. Funding of US biomedical research, 2003-2008. JAMA. 2010;303(2):137-143.

52. Kaiser J. Biomedical research. Rejecting 'big science' tag, Collins sets five themes for NIH. Science. 2009;325(5943):927.

53. Rust G, Cooper LA. How can practice-based research contribute to the elimination of health disparities? J Am Board Fam Med. 2007;20(2):105-114

54. Hasnain-Wynia R, Baker DW. Obtaining data on patient race, ethnicity, and primary language in health care organizations: current challenges and proposed solutions. Health Serv Res. 2006;41(4 Pt 1): 1501-1518.

55. Institute of Medicine. Future Directions for the National Healthcare Quality and Disparities Reports. Washington, DC: National Academy Press; 2010.

56. Hong CS, Atlas SJ, Chang Y, et al. Relationship between patient panel characteristics and primary care physician clinical performance rankings. JAMA. 2010;304(10):1107-1113.

57. Wang CJ, Conroy KN, Zuckerman B. Payment reform for safetynet institutions-improving quality and outcomes. $N$ Engl J Med. 2009;361(19):1821-1823.

58. Katerndahl DA, Wood R, Jaén CR. A method for estimating relative complexity of ambulatory care. Ann Fam Med. 2010;8(4):341-347.

59. Starfield B. Family medicine should shape reform, not vice versa. Fam Pract Manag. 2009;16(4):6-7.

60. Roblin DW, Howard DH, Ren J, Becker ER. An evaluation of the influence of primary care team functioning on the health of Medicare beneficiaries. Med Care Res Rev. Sep 9, 2010 [Epub ahead of print].

61. Schuetz B, Mann E, Everett W. Educating health professionals collaboratively for team-based primary care. Health Aff (Millwood). 2010;29(8):1476-1480. 